\title{
The Origin and Dispersion of Human Parasitic Diseases in the Old World (Africa, Europe and Madagascar)
}

\author{
Jean-Pierre Nozais
}

\author{
32 Av. des Bas Chaumiers, 91170 Viry-Chatillon, Paris, France
}

\begin{abstract}
The ancestors of present-day man (Homo sapiens sapiens) appeared in East Africa some three and a half million years ago (Australopithecs), and then migrated to Europe, Asia, and later to the Americas, thus beginning the differentiation process. The passage from nomadic to sedentary life took place in the Middle East in around 8000 $B C$.

Wars, spontaneous migrations and forced migrations (slave trade) led to enormous mixtures of populations in Europe and Africa and favoured the spread of numerous parasitic diseases with specific strains according to geographic area.

The three human plasmodia (Plasmodium falciparum, P. vivax, and P. malariae) were imported from Africa into the Mediterranean region with the first human migrations, but it was the Neolithic revolution (sedentarisation, irrigation, population increase) which brought about actual foci for malaria.

The reservoir for Leishmania infantum and $\mathrm{L}$. donovani - the dog - has been domesticated for thousands of years. Wild rodents as reservoirs of $\mathrm{L}$. major have also long been in contact with man and probably were imported from tropical Africa across the Sahara. L. tropica, by contrast, followed the migrations of man, its only reservoir.

L. infantum and L. donovani spread with man and his dogs from West Africa. Likewise, for thousands of years, the dog has played an important role in the spread and the endemic character of hydatidosis through sheep (in Europe and North Africa) and dromadary (in the Sahara and North Africa).

Schistosoma haematobium and S. mansoni have existed since prehistoric times in populations living in or passing through the Sahara. These populations then transported them to countries of Northern Africa where the specific, intermediary hosts were already present.

Madagascar was inhabited by populations of Indonesian origin who imported lymphatic filariosis across the Indian Ocean (possibly of African origin since the Indonesian sailors had spent time on the African coast before reaching Madagascar). Migrants coming from Africa and Arabia brought with them the two African forms of bilharziosis: S. haematobium and S. mansoni.
\end{abstract}

Key words: human migration - malaria - leishmaniasis - hydatidosis - bilharziasis - lymphatic filariosis - Mediterranean Madagascar - Africa

According to Y Coppens (Blanc 1984), some 7 million years ago, the large longitudinal Rift separated two populations of primates: one population which remained west of the Rift and lived in the equatorial forest, giving rise to chimpanzees and gorillas; another population which was east of the Rift and evolved in a more open environment (thus more favourable to the upright position), giving rise to the prehominids (Australopithecus) around 3,5 million years ago. These latter populations preceded the appearance, some 2 million years ago, of the Homo habilis and then, 200,000 to 300,000 years later, that of the Homo erectus, our direct ancestor.

Thus, over one million and a half years ago, small groups of men - hunters and gatherers - left the savannahs of East Africa and migrated slowly towards North Africa, the Middle East, Asia and Europe (Leakey estimates that they migrated at a rate of 50 to $100 \mathrm{~km}$ by generation).

Fax: +33-1-69-05.5542. E-mail: sgbalta@pasteur.fr Received 26 August 2002

Accepted 25 November 2002
Neanderthal man occupied Europe and West Asia, from the Mediterranean to the Red Sea and to Belgium, from the Atlantic coast to present-day Central Asia (Renault \& Daget 1980) but was replaced in Europe from 30,000 to 35,000 years ago by Homo sapiens sapiens who probably came from Asia where he had already established himself (Blanc 1984). In Sub-Saharan Africa, on the other hand, modern man was already present some 50,000 years ago.

According to Chaline (1982), man explored Europe between 1,5 million and 700,000 years. There are numerous vestiges testifying to the presence of prehistoric man in the palaeolithic period 800,000 to 900,000 years ago: traces have been found in Morocco, in Italy and Provence, in the Jordan Valley, and Syria (Hours 1982).

Whereas formerly small tribes had moved constantly in search of animals and comestible plants, the first villages appeared around 8,000 years BC; remains have been found in Yugoslavia (Lepenskivir), in Macedonia, and in Jericho (7,800), near to Mossoul (Leakey \& Levin 1985, Nougier 1977). The first actual town was found in Anatolia, in Catal Huyuk (7,000 BC). Agriculture and breeding of animals appears to date from 10,000 years ago and constituted a veritable revolution, rendering man sedentary. It would seem that the fertile lands of the southwestern Mediterranean area were the first to see this new way of life develop (Blanc 1984, Clarke 1980, Leakey \& 
Levin 1985). Navigation on the Mediterranean is relatively recent, dating back some 13,000 years.

The history of Egypt and ancient Greece, the campaigns of the Pharaohs, the Hittites (originally from Anatolia), the Babylonians and then of Alexander the Great, the formation of the Roman and then Byzantine Empire, finally the Islamic conquest and the crusades are part of common knowledge. These events brought about a major mixing of populations (and of cultures) and favoured the spread of certain parasitic diseases. Nor should one forget that for some two thousand years slaves made up a large part of the population in Athens, Rome and later in Cordu, Bagdad and so on. According to Lombard (1971), the slaves of the Muslim Mediterranean world came from Europe, Turkestan and Black Africa. Caravans of black slaves crossed central and eastern parts of the Sahara. These slaves certainly brought with them certain parasites which found in their "adoptive" land favourable climatic conditions so that they established themselves durably in the area.

Man is the main and probably even the only element responsible for the disappearance of the Mediterranean forest which was replaced years ago by scrub or moor land. This disappearance had several causes: (a) the use of wood for domestic purposes (the two oldest prehistoric sites with traces of fire places date from $450,000 \mathrm{BC}-$ Verteszlollos near Budapest - and 400,000 years - Terra Amata in Nice (Clarke 1980, Nougier 1977); (b) the development of copper and iron work first in eastern areas and then in western; the ovens used were rudimentary and consumed enormous amounts of wood; (c) the spread of sheep and goat breeding which came about some 10,000 years ago (Nougier 1977). Sheep as well as goats are well known destroyers of vegetation and in particular of young sprouts; (d) clearing by fire or by axe which began between 5,000 and 3,500 years before our era according to region (Clarke 1980, Nougier 1977); (e) especially the development of navigation on the various Mediterranean seas; the construction of ships both for war and for trade required large quantities of wood which accelerated deforestation. Lombard (1971) showed for example that as early as the 11th century the Islamic population was obliged to seek their wood far a field from the Mediterranean and that the decadence of the Islamic world went hand in hand with the disappearance of war and trade fleets. The only trees one still finds are lemon, olive, and date palm trees (especially in oases), almond trees - none of which can be used for the construction of ships but can be for domestic fires and mud walls of houses.

There has never been any evidence of a racial influence on the evolution of a parasitic disease (in relation with particular HLA groups, for example) except in the case of hemoglobin S, which was widespread in populations originating from Black Africa; however hemoglobin $\mathrm{S}$ does not intervene in the sensitivity to Plasmodium falciparum, and the absence of the Duffy antigen prevents the intra-erythrocyte development of $P$. vivax. The parasite is thus considered the only element responsible for the singular characteristics of the disease in human beings according to antigenic character (thus strains or varieties within each parasitic species).
Theoretically, the constitution of specific strains may come about as a result of various combined or isolated causes: (a) migrations of human populations bringing their own strains from elsewhere; (b) long-term isolation of human groups (a naturally occurring phenomenon on islands) has brought about selections of parasitic strains; (c) formation and isolation in situ of strains (or populations) of parasites, primitively enfeoffed to certain invertebrate and certain inferior vertebrate. In this case and on the condition that the host-parasite relations are prolonged, genetic variations occur, rendered necessary by the adaptation of the parasite to its host(s) (synthesis by the parasite, host proteins, antigenic variations of trypanosomes, etc.).

\section{MALARIAL DISEASE AND THE MEDITERRANEAN WORLD}

The history of malaria is closely interwined with that of humanity. It seems highly probable that the ancestors of Homo sapiens already suffered from tertian or quartan fevers since their intermittent and seasonal characteristics in temperate zones as well as their apparent link to stagnant waters in ponds and swamps had drawn the attention of keen observers since Antiquity. Although $P$. malariae is considered a natural parasite of chimpanzees (Bray \& Garnham 1982), it is commonly accepted that man constitutes the main animal reservoir (with, in a temperate climate, vector anopheles which preserves the parasite during their winter hibernation) of the three plasmodia affecting the Mediterranean world: P. falciparum, P. vivax and $P$. malariae (in spite of the presence, for more than 2,000 years, of a black population in southern and eastern Mediterranean countries, $P$. ovale, a plasmodium prevalent in tropical Africa from where the black slaves were "imported", never took root in these countries).

For malaria to be transmitted and lastingly endemic, a certain number of biological conditions with regard both to anopheles and man must be met: in temperate climates the life span of an adult anopheles is variable; Anopheles atroparvus live from 6 weeks to 6 months. Furthermore, anopheles who hatch before the cool season and are possibly infected with the parasite after their blood meal, remain in hibernation until the return of a sufficiently high outside temperature (that is, above $15^{\circ} \mathrm{C}$ ). The activity and thus the spread of malaria can take place only in spring and especially in summer, however the insect can become active in the event of even artificial, temporary elevation of temperature - for instance, in a prehistoric cave heated by fire. On the other hand, in temperate climates, the survival rate of anopheles is poor.

The speed of development of Plasmodium in the mosquito depends on the species of parasite and on the outside temperature. For the same length of evolution over one month, the temperature necessary for $P$. vivax and $P$. falciparum to develop is respectively $15^{\circ}$ and $19^{\circ} \mathrm{C}$.

Parasite infected mosquitoes do not all transmit the parasite, nor do all human carriers of gametocytes infect the mosquitoes. The density of both carriers and vectors is thus of great importance.

$P$. vivax and $P$. malariae persist for several years in the human organism and in the total absence of reinfection, however fewer than 5\% of carriers of P. falciparum 
remain infected for over 6 months (and in general for less than a year).

One may consider that the three plasmodia were imported from Africa to the Mediterranean world during the very first human migrations. The hunters and gatherers of prehistory seem to have made their way slowly, in small groups of several dozen, through North Africa, the Near East and Europe. It seems likely that they remained throughout several months in a given greater or smaller region depending of the availability of food. They were thus perfectly capable of creating small endemic foci of malaria, which would have been regularly supplied with parasites, including $P$. falciparum, with each new wave of visitors.

However, malaria foci undoubtedly attained their full means of expansion with the Neolithic revolution, 8,000 to 10,000 BC. Sedentary life, the formation of the first villages and towns, clearing and irrigating crops, the increase in human population (thanks notably to the improvement in living conditions and food) certainly favored the spread of malaria even if the proximity of domestic animals may have allowed for a trophic deviation, with anopheles, zooanthropophiles, biting more animals than men. It is certain that repeated "imports" of parasites occurred throughout the history of the Mediterranean world: the Phoenicians and Athenians when founding their colonies respectively in Carthage and in Sicily and Provence, brought with them their own plasmodia, just as Hannibal's armies did when they crossed Spain and when the Carthaginian army sojourned in Northern Italy.

We know for sure that malaria, including in its most severe form of $P$. falciparum, existed in the Mediterranean world from the time of Antiquity since several famous men died from it: Alexander the Great had contracted malaria in Babylon in 323, Alric was infected in the Pontine Marshes in the 5th century, Dante in 1321 and so on. It was likewise malaria (and geese) which prevented the Brennus Gauls from penetrating the Capitol, and the Assyrians from taking Jerusalem (Coudert 1979). As Hippocrates has described, malaria was prevalent throughout the Mediterranean world from prehistoric times to our day; each military expedition, each army brought with it new strains of plasmodia which mixed with earlier strains to spur often devastating epidemics.

The Roman Empire and the conquering Muslims had already understood the nefarious effects of swamps and mosquitoes and had undertaken draining and drying out procedures for stagnant water (Blanc 1977).

\section{VISCERAL AND CUTANEOUS LEISHMANIASIS IN ANTIQUITY}

Visceral and cutaneous leishmaniasis (Africa and countries of the Mediterranean basin) fall into four complexes of species and geographic spread: (1) Leishmania major complex in Africa north of the Sahara, in the Near East and, the Arabic peninsula; (2) L. tropica in Eastern Europe, the Near East, and Tunisia; (3) L. infantum in the Western Mediterranean; (4) L. donovani in the Far East.

Domestic and wild Canidae are the reservoir hosts of the $L$. donovani and $L$. infantum complexes and the dog plays a major role in the epidemiology of both types of leishmaniasis.
The origin of the dog and of his domestication have not been definitively established. Certainly, man and dog are complementary with the former providing the latter with easy nourishment through his own leftovers, and the dog serving as guard, an excellent assistant in hunting, as well as a beast of burden, and even a potential reserve of meat.

The domestic dog Canis familiaris may be descendant from a wild breed C.f. poutiatini or from the wolf $C$. lupus pallipos (wolf of Syria, wolf of Spain, wolf of Japan); the jackal on the other hand is no longer thought to have given rise to domestic dogs because of his very solitary habits (Petter 1972).

Although a Spanish rupestral painting indicates that the nomad hunters-gatherers probably used dogs to help them hunt some 18,000 (or even 50,000) years ago, true domestication must have taken place with man's sedentary lifestyle. Dog bones, 8,000 years old, have been found in Shanidar in Iraq (associated with sheep bones); the dog lived with man in the villages of Cyprus some 5,500 years ago, as well as in Greece, 500 years earlier (Neanicomedia), and in the Egyptian Nile Valley some 7,000 years ago (Nougier 1977).

These close contacts reaching far back in time between man and dog - the reservoir of leishmania - probably led to the sporadic appearance of human kala-azar as soon as the first Mediterranean villages were founded.

Today, the domestic dog is the principal reservoir of leismaniasis for man, but foxes and jackals were also carriers of L. donovani and L. infantum in many areas of the Mediterranean basin (Dedet 1976, Benallegue \& Tabbakh 1978, Morengo et al. 1984, Ashford 1986, Leblancq \& Peters 1986,) and may have been a (rare) source of infection for man since they were hunted in prehistoric times until fairly recently either in order to get rid of them, or for their fur or else for pleasure.

Numerous species of wild rodents are reservoirs of $L$. major and they were in contact very early with man who hunted them for their fur or their meat and who drove them from their ambush when preparing fields for sowing. For this reason, it seems highly probable that the epidemiology of this rural cutaneous leishmaniasis has not changed since man's arrival in these Mediterranean foci. The main rodent reservoirs are: Meriones, Rhombomys and Psammomys. On the other hand, L. tropica for which the dog is a secondary and accessory reservoir in Greece and the Near East (Leblancq \& Peters 1986) is essentially a human parasite responsible for urban cutaneous leishmaniasis (Ashford 1986, Rioux et al. 1986). Ashford (1986) in particular believes that L. tropica's adaptation to man goes back very far and was thus spread from its original focus in East Africa through human migrations. The same author considers that L. major - which is the parasite of a wild rodent, Arvicanthis, in Senegal only - to be originally from that part of Black Africa which subsequent, successive adaptation to Meriones, Rhombomys and Psammomys. We know indeed that the desertification of the Sahara is recent, since it had begun only 4,000 years $\mathrm{BC}$ and that between 15,000 and 500 BC the existence of humidity and abundant vegetation in the area linked Southern Africa to its northern parts. 
The Montpellier school has shown (Morengo et al. 1986) that the L. infantum complex was present only in central and western Mediterranean areas with three zymodemes for visceral forms and five zymodemes for cutaneous forms; $L$. infantum MON 1 is responsible for Mediterranean visceral zoonotic leishmaniasis. The same authors suppose that the two complexes, $L$. donovani and $L$. infantum separated 2 million years ago and diversified in the Pleistocene or perhaps even in modern times. Furthermore it appears that the L. donovani complex originates from East Africa (like man), and is present in the Near East, in the Arabic peninsula and in Asia with eight zymodemes (Rioux 1985). It seems to have been transported by man towards the east when, having reached the Near East, one group of men when east and the other west.

L. major, a parasite of rodents, probably originated in Black Africa in countries bordering on the present-day Sahara. Its spread toward the Mediterranean may have occurred when the Sahara was a humid area, rich in fowl and pastures between 15,000 and 500 BC.

L. tropica and $L$. donovani sensu lato have a common ancestor, come from East Africa and separated probably some 2 million years ago at the same time that $L$. donovani sensu stricto and $L$. infantum were progressively acquiring increasingly individual traits until the Pleistocene.

L. tropica, a strictly human parasite spread with man during his migrations: L. donovani s.s and L. infantum transported by man (and perhaps by partially domesticated dogs or rather dogs as commensals of small groups of human beings) separated in the Near East into an eastern strain, L. donovani s.s and a western strain, L. infantum, which then spread around the Mediterranean.

Killick Kendrick (1985) sees the parasite as having evolved simultaneously with the vector which would explain the diversity both of the phlebotomes and the leishmanias resulting from their mutual adaptation: "the diversity of the morphologically close species of Larrousius in the Mediterranean basin suggests a relatively recently evolution of the group in this region following the arrival of the ancestral form (of the phlebotome), after the disappearance of the "Ihetis sea in the late Miocene word, some 5 to 6 million years ago". Vector phlebotomes were thus already installed in the Mediterranean basin well before the arrival of man and were already feeding on rodents and wild canidae who were well established on the shores of the Mediterranean.

\section{HYDATIDOSIS IN THE ANCIENT WORLD (AFRICAN AND MEDITERRANEAN BASIN)}

With the exception of Turkana in Kenya, the Mediterranean Basin is the largest and most important focus of human and animal hydatidosis with regard to incidence in human and veterinarian medicine.

The dog plays a major role in the epidemiology of human disease. As already indicated above, the dog lives in close quarters with man, feeding on scraps, on the offal of wild herbivores hunted by his master or domestic herbivores bred for butchering. The dog soils with his excrements, the floors of houses, villages, and the village area. Next to the domestic dog, the role of wild dogs and jack- als is less important today. But this was certainly not the case for prehistoric man who hunted jackals for food and fur. Therefore, it seems probable that human hydatidosis existed at the very beginnings of humanity. Man's sedentary lifestyle, the domestication of various herbivores after that of the dog during the Neolithic revolution undoubtedly favoured the spread of the disease in villages.

The domestic sheep is very likely a descendant of the wild sheep (it is not sure that the bones found in Shanidar in Irak in the sites of dwelling from the 9th millennium BC are those of domestic sheep). It seems that Neolithic hunters caught, and then domesticated, wild sheep in the Near East and in Asia Minor (especially on the Iranian plateau). In any case, at the end of the Mesolithic era there were herds of domestic sheep, around the Caspian Sea, some 6,000 to 5,000 BC. There were also such herds in Corsica and Cyprus, around 5,500 years before our era as well as in Greece, in Nicomedia 600 years earlier, but they did not reach the western Mediterranean area, at least notably, until the 3rd millennium. It is believed that the spread of the domestic sheep throughout the Mediterranean basin took place in three successive waves from the Near East and Mesopotamia. Then the Romans played a role in its spread towards Northern Europe.

Later, and almost until our times, large moving of flocks accompanied by their shepherds and dogs, covered the mountain slopes and the roads of the Mediterranean plains, certainly contributing thereby to the spread of hydatidosis among dogs and inhabitants of the plains. There is only one species of wild goat, Capra aegragus, from which the domesticated goat is derived: $C$. hircus. The first traces of domestication were found in the Near East, in the Jordan Valley (6,700 years BC), in the region of Bagdad (3,000 BC) and in Egypt, where the Nubia ibex appears to have been domesticated at 4,000 years BC.

Whereas the bovine species are often infected with parasites, in the Mediterranean Basin they seem to have played only a very secondary role in the long-lasting endemic character of the disease. This is because, in these animals, hydatids are rarely fertile and thus less infective to dogs. In the Mediterranean Basin, domestic bovines are descendant from the auroch, Bos primigenius and from the zebu. Traces of the auroch have been found in the Nile Valley going back to the 4th millennium BC, and other traces in the form of statues, hieroglyphics, and paintings have been found dating from 3,200 BC. In this regard, the cult of sacred cows in Egypt and of the sacred bull in Greece (Minotaur legend) should not be forgotten. The zebu has been identified in Mesopotamia on a Sumerian vase from 2,800 to $2,700 \mathrm{BC}$, and probably spread later to the borders of the western Mediterranean and Egypt. In the western Mediterranean area, the auroch was domesticated as early as the 4th millennium BC.

Whereas the domestic sheep played a primary role as intermediary host of the Echinoccoccus tapeworm, there were other hosts and the sheep tended to be replaced, in the south and the east, by the dromedary.

The dromedary was common in North Africa and the Near East, where there were large herds led by nomads and served as transport vehicles between arid areas of the desert. Its domestication seems to have begun in cen- 
tral Arabia in the 4th millennium BC, and then was introduced into Africa by the Ptolemies who had brought it back from the Near East and made it common in Fezzan and in the Sharan mountain mass in the 2 nd and 3rd century BC. Caravans of dromedaries, a pack-saddle animal, replaced the horse and chariot and by the 4th century reached the Western Sahara, the Atlantic coast, and southern Morocco (Cornevin 1967). It is likely that the animal spread in a similar fashion in East Africa. Hence, we believe that hydatidosis was introduced into the Magrab, Egypt, Libya and Turkana by the dromedary; the parasite then found dogs, other canine species, herbivores, and thus continued to spread until it reached man; the present-day spread of the desert towards the south and human migrations from Sahel could similarly and massively introduce the parasite into tropical Africa.

\section{BILHARZIOSIS IN THE ANCIENT WORLD (TROPICAL AFRICA AND THE SAHARA)}

The existence of a remarkable clinical symptom, hematuria, had allowed physicians in ancient Egypt to characterize - it would seem - urogenital bilharziosis. Urogenital bilharziosis is mentioned in the Ebers papers written in 1,500 BC. Hematuria was also known in Mesopotamia as witnessed to by a text written in cuneiform on an Assyrian landmark.

The discovery of $S$. haemotobium eggs in the bladder of mummies embalmed earlier than 1,200 BC is further proof of how old this human disease is. Similarly, a paleolithic site in the Egyptian desert had preserved shells fossilized with Bulinus truncatus and Biomphalaria alexandrina (Wendorf et al. 1976). The presence of the intermediary host of $S$. mansoni in this region appears to confirm that intestinal bilharziosis was long known in Egypt, but the absence of salient clinical signs probably explains why there has been no trace of the disease found in the writings of the ancient peoples from eastern Mediterranean regions. B. pfeifferi and B. truncatus have been found north of Mali (Petit-Maire 1984).

Mandahl Bahr (1959) has pointed out the existence of B. tchadiensis in the area of the Tchad Lake as well as of B. germani, also found in the Sahara. Thus, it seems likely that $S$. mansoni existed in prehistoric times in Saharan populations, associated with $S$. haematobium (its disappearance from desert areas can be explained by the impossibility of its intermediary hosts to survive periodic drying out of resting-places).

Hence the spread of both forms of bilharziosis on the borders of the Mediterranean area must have taken place in successive waves with prehistoric men and nomad populations criss-crossing the area and coming as much from the Nile Valley as from the South, the Sahara and Black Africa. The Assyrians and Carthaginians, Egyptians, Romans, Arabs, crusaders, and black slaves - all of whom traversed the area - contributed to fuelling and/or circulating new foci. The origins of the two Mediterranean forms of schistosomiasis are thus many and strains of bilharziosis in certain foci may well have different genetic characteristics from the Egyptian or South Saharan ones. In this context, it should be noted that the intermediary hosts of S. haematobium are different north and south of the Sa- hara (B. truncatus in the north and B. africanus in the south).

The comparison of two cultures of $S$. mansoni in Egypt and one in Saudi Arabia has revealed the great genetic homogeneity existing between them and, likewise, the fact that the foci of the Arabic peninsula were constituted from strains coming from the Nile Delta. These strains may well have been brought by the caravans drawn by dromedaries which have circulated for thousands of years in the area or by pilgrims coming from Egypt or Black Africa.

In 1927, Bettencourt and Borges (1927) identified and studied the Portuguese foci in the Algrave province (in the South of the country). It was there that these same authors described the Estor and Tavira foci with their intermediary host Planorbirus metidjensis var. duforni. Later, Fraga de Azevedo (1969) discovered the European sub-species of $S$. haematobium in the Portuguese focus and called attention to the existence of $B$. contortus alongside $P$. metidjensis in both the North and the South of the country.

Although all authors agree that the parasite originated in Northern Africa, its date of arrival is debated: either as early as the prehistoric era, or later during the Roman occupation, by the incursions of the Maures, or as late as 711 with the arrival of the Islamic armies with Egyptian soldiers (Bettencourt \& Borges 1972). This Portuguese focus is now dormant and has not been aroused by the arrival of European coming from Angola after the colony gained independence.

\section{AN INTERESTING CASE: MADAGASCAR}

Throughout the primary era, until the end of the Permian, Madagascar was integrated in the Gondwana continent along with Africa and India; 225 million years ago (between the Permian and the Triassic), the progressive formation of the Mozambique Canal separated the island from the continent but throughout the secondary era, the Euroafrican region provided Madagascar with fauna and flora. At the closing of the Inferior Cretaceous, some 100 million years ago, India and Australia broke off successively from Madagascar. But whereas during the tertiary era, Africa's and Madagascar's coasts were still linked by marshland, Madagascar became a veritable island starting with the Pliocene era (over 5 million years ago) (Deschamp 1968, Termier \& Termier 1969).

This isolation explains the characteristics of the island's fauna. Whereas fossil remains of dinosaurs of the Middle Jurassic and the Superior Cretaceous (Bothriospondylus dinosaurus for example) (Taquet 1979) resembling dinosaurs from India and Patagonia have been found in north-western parts of the island, only non venomous Boidae and Colubridae were able to migrate to Madagascar, which explains the total absence of poisonous snakes on the island despite 28 different species of chameleons, 4 endemic turtles and Crocodylus niloticus (Dorst 1969, Rage 1982). There were no ungulates before man came on the island, there are no large carnivores either (Ribot \& Coulanges 1982); which explains the development and diversification of the carnivore viverrides $(10$ species), endemic insectivores and especially 40 species 
of lemuridae: Lemur types with Lemur catta, Hapilemur, Lepilemur and forest Cheirogaleus, Microcoebus, Allocebus, Phaner, Prophithecus and finally Avahi lanigher, Indri indri and Daubentonia madagascarensis (Aye aye) (Dorst 1969, Petter 1972).

There are numerous domestic species but none originated in the area.

The human population of Madagascar came from Indonesia, Africa, Arabia, and Europe.

The Indonesians probably came before the first millennium $\mathrm{BC}$, but it is difficult to set a more precise date. Generally, the second half of the first millennium is suggested, which would indeed explain the fact that hemoglobin $\mathrm{E}$ - present between the 9th and the 11th century in the Khmer Empire - was not imported with the first invaders of the island (Bernard 1985). The Indonesians appear to have arrived either right after a $6,000 \mathrm{~km}$ sea crossing or, in greater likelihood, by following the Indian and then the West African coast lines. They may well have stayed over in Africa, mixing with the black population before colonizing what was still a virgin island with their pigs and cattle (Cornevin 1967, Deschamp 1968). The most ancient Arab site, the Waquaq island (Arab name for Madagascar) dates from $970 \pm 100$. The Arab merchants opened up shop on the north-western and eastern coasts, probably in the 12th century. They brought with them black slaves from their African shops. Another population, a mix of Arabs, Madagascans and Africans, came from the Comoros to the north-western coast: the Anataotes (Cornevin 1967). The arrival of the first Europeans (Diego Das, the Portuguese) dates from the 1500s. Then came the English and the French, with the latter instituting the Protectorate of Madagascar by the treaty of 1885 .

Thus, Madagascar is characterized by a geographical isolation of several million years and a recent population - Asian, African and Arab. These two characteristics must be borne in mind in order to understand the origins of parasitic agents which do not affect the people of Madagascar today.

Fontoynot and Robert demonstrated the presence of lymphatic filariasis in Madagascar in 1909. In 1955, Galliard and Brygoo established that nocturnal microfilaria found in man had a size and shape and belonged to Brugia malayi even though with regard to their internal morphology they were different, they therefore created a new Wucheria bancrofti var. vauceli variety.

In 1958, Chabaud and his collaborators (Euzéby 1961) described the morphological identity of the Madagascar microfilaria found in man as well as of Dipetalonema petteri parasite of Lepilemur ruficadatus. However, today it is considered to be a classical W. bancrofti of which there exists a large human focus on the western coast. The vectors are A. gambiae, A. funestus, and Culex pipiens sl. (Coulanges 1982).

In West Africa, human foci of wuchereriosis are few in number and scattered: the parasite is transmitted by the two above-mentioned anopheles and also by $C$. pipiens fatigans (not a vector in Madagascar for want of the parasite's capacity to adapt).

In South-East Africa, W. bancrofti is frequent, wide- spread by Anopheles, Culex and Aedes. B. malayi, nonexistent in New Guinea and Australia, is a parasite of primates and wild carnivores, spread by Anopheles and Mansonia. It had certainly adapted to man a thousand years ago.

Therefore, we believe that the African and/or Asian origin of W. bancrofti present in Madagascar is beyond doubt, with the long life cycle of the parasites in the human body having facilitated their transportation far afield even by slow navigation. If one accepts also the existence of the vauceli variety on the island, two hypotheses may be advanced: either it is a geographic variety of $B$. malayi brought by the first invaders from their far off Asiatic focus which then adapted to the lemurs and local vectors (the capacity of the filaria to adapt to different culcidae is well known) (Coulanges 1982), or else it is a local filaria parasite of lemurs (as Chabaud thinks) and which only accidentally and rarely infects man.

\section{BILHARZIASIS}

B. pfeifferi pfeifferi is the only intermediary host of $S$. mansoni, it is identical on both sides of the Mozambique Canal. B. obtusispira, distinct from B. liratus (incompatible with the development of $S$. haematobium), is part of the africanus species such as $B$. (Ph) africanus africanus, which was hard to distinguish for Mandahl Bahr (1959), and $B$. $(P h)$ globosus which occupies all of Africa south of the Sahara. B. (B) cernicus exists only in Mauritius.

The existence on both sides of the Mozambique Canal of the same species of molluscs responsible for the spread of human bilharziasis clearly demonstrates a common origin dating from the long period during which Madagascar, as part of the Gondwana continent, was attached to Africa. But the present-day island distribution of Biomphalaria and bulins is very particular: B. pfeifferi pfeifferi exists only on the east coast - the high plateaux with a few foci dispersed in southern and south-western areas, whereas B. obtusispira is widely distributed in particular on the western and north-western coasts. Furthermore, it is known that $B$. pfeifferi pfeifferi cannot survive long periods of drying out of its aquatic resting-places and that the temperature of the water must not be below $30^{\circ} \mathrm{C}$ in the resting-places of B. obtusispira or else the egg-laying may be slowed down or suppressed altogether (Moyrou et al. 1982). It is probable that at a given time in geological history, and well before man's arrival on the island, the two species of molluscs were more evenly spread out, but that the appearance of prolonged drying out on the western coast or a lasting cooling down on the eastern coast brought about the disappearance of one of the two species unable to adapt to the climatic changes.

Both forms of bilharziasis in Madagascar are of African origin and were brought by man. Since Arab populations and possibly also Asiatic populations spent time on the West-African coasts, they brought $S$. haematobium with them to the north-western coast of Madagascar (Brygoo et al. 1965). The contamination of (bulins) on the western coast may have two sources: Arab populations but also Black populations who crossed over the Mozambique Canal on their own or as slaves of the former. These same Africans also imported to the island S. mansoni as is shown in par- 
ticular by the identical sensitivity of the worm to oxamniquine on both sides of the Canal.

\section{REFERENCES}

Ashford DW 1986. Spéculations on the Origin and Evolution of Old World Leishmania System, OMS/INSERM, Montpellier, p. 257-264.

Benallegue A, Tabbakhe E 1978. La leishmaniose viscérale en Algérie. Med Trop 38: 425-433.

Bernard J 1985. Le sang témoin et pilote de l'histoire. Sem Hôp Paris 61: 3259-3268.

Bettencourt A, Borges L 1927. La bilharziose au Portugal. Bull Soc Pathol Exot 20: 350-365.

Blanc F 1977. Histoire du paludisme. In Histoire de la Médecine, de la Pharmacie, de l'Art Dentaire et de l'Art Vétérinaire, Tome 7, Albin Michel, Laffont, Tchou, Paris.

Blanc M 1984. L'histoire génétique de l'espèce humaine. La Recherche 155: 654-669.

Bray RS, Garnham PCC 1982. The life cycle of primate malaria parasite. Br Med Bull 38: 117-122.

Brygoo ER 1965. Les bilharzioses humaines à Madagascar. Arch Int Pasteur Madagascar 33: 79-106.

Brygoo ER, Moreau JP 1966. Bulinus obtusispira (CA Smith, 1886) hôte intermédiaire de la bilharziose à S. haematobium dans le Nord-ouest de Madagascar. Bull Soc Pathol Exot 59: 835-839.

Chaline J 1982. L'Évolution Biologique Humaine. Que sais-je? PUF, Paris.

Clarke R 1980. Naissance de l'Homme, Seuil, Paris.

Cornevin R 1967. Histoire de l'Afrique des Origines au XVIe Siècle, Payot, Paris.

Coudert J 1979. Histoire des Découvertes du Paludisme, Inst Hist Med. Université Cl Bernard Lyon Fond, Mérieux.

Coulanges P 1982 (1983). Quelques données sur la filariose lymphatique à W. bancrofti à Madagascar. Arch Inst Pasteur Madagascar 50: 169-184.

Dedet JP 1976. La leishmaniose viscérale dans le monde. Etapes des connaissances, répartition géographique et fréquence. Bull Inst Pasteur 74: 413-434.

Deschamp H 1968. Madagascar, PUF, Paris.

Dorst J 1969. Les Iles, berceaux d'espèces nouvelles. In La Vie des Animaux, Tome 1, Larousse, Paris.

Euzéby J 1961. Les Maladies Vermineuses des Animaux Domestiques. Tome 1: Maladies Dues aux Némathelminthes, Vignot, Paris, p. 189.

Fraga de Azevedo J 1969. Relations biologiques parmi les différentes souches géographiques du complexe $S$. haematobium. Bull Soc Pathol Exot 62: 348-374.

Gaillard H, Brygoo ER 1955. Microfilaria bancrofti var. vauceli variété nouvelle de la côte Sud-Est de Madagascar. Bull Soc Pathol Exot 48: 473-475.
Hours F 1982. Les Civilisations du Paléolithique: Que sais-je? PUF, Paris.

Killick Kendrick R 1985. Some epidemiological consequences of the evolutionary fit between Leishmaniae and their phlebotome vectors. Bull Soc Pathol Exot 78: 747-755.

Leakey RE, Levin R 1985. Les Origines de l'Homme, Flammarion, Paris.

Leblancq SM, Peters W 1986. Leishmania in the Old World. The distribution of $L$. donovani s.l. zymodemes. Trans $R$ Soc Trop Med Hyg 80: 367-377.

Lombard M 1971. L'Islam dans sa Première Grandeur, Flammarion, Paris.

Mandahl-Barth G 1959. Les Hôtes Intermédiaires de Schistosomes, OMS, Genève, Monographie no. 37.

Moreno G, Rioux JA, Lanotte G, Bratlong F, Ferre S 1986. Le Complexe L. donovani s.l. L'Analyse Enzymatique et Traitement Numérique. Individualisation du Complexe L. infantum. Corollaire Biogéographique et Phyletiques. A Propos de 146 Souches Originaires de l'Ancien et du Nouveau Monde, CNRS/INSERM, Montpellier, p. 105117.

Moyroud J, Breuil J, Dulat CH, Coulanges P 1982 (1983). Les mollusques hôtes intermédiaire des bilharzioses humaines à Madagascar. Etat actuel des connaissances. Arch Int Pasteur Madagascar 50: 39-65.

Nougier LR 1977. L'Économie Préhistorique, Que sais-je?, PUF, Paris.

Petit-Maire N 1984. Le Sahara de la steppe au désert. La Recherche 160: 1972-1382.

Petter F 1972. L'origine des mammifères domestiques. In La Vie des Mammifères, Bordas, Paris.

Petter JJ 1972. Sous-ordre des Prosimiens. In HS Schultz, Les Primates, Bordas, Paris, p. 340-351.

Rage JC 1982. L'histoire des serpents. Pour la Science 26: 1627.

Renault F, Daget S 1980. La traite des esclaves en Afrique. Etudes Scientifiques 1: 69.

Ribot JJ, Coulanges P 1982 (1983). Les zoonoses à Madagascar. Arch Inst Pasteur Madagascar 50: 147-166.

Rioux JA 1985. Chorologie et phylogenèse des leishmanioses. Bull Soc Pathol Exot 78: 780-781.

Rioux JA, Petter F 1986. Les Leishmanioses Cutanées du Bassin Méditerranéen Occidental, Coll. Int CNRS/INSERM 1984, Montpellier, p. 365-395.

Taquet $P$ 1979. Le règne des dinosaures. Pour la Science 23: 72 90.

Termier G, Termier M 1969. La mise en place des faunes passées et actuelles. In La Vie des Animaux, Tome 1, Larousse, Paris.

Wendorf F, Schild R, Said R 1976. The prehistory of the Egyptian Sahara. Science 193: 103-114. 